\title{
Wait times from presentation to treatment for colorectal cancer: A population-based study
}

\author{
H Singh MD MPH ${ }^{1}, C$ De Coster PhD RN MBA ${ }^{2}$, E Shu MSc $^{3}$, K Fradette $M A^{3}$, S Latosinksy MD MSc ${ }^{2,4}$, \\ $M$ Pitz MD MHS' ${ }^{1}$ M Cheang M Math², D Turner $\mathrm{PhD}^{2,3}$
}

\begin{abstract}
H Singh, C De Coster, E Shu, et al. Wait times from presentation to treatment for colorectal cancer: A population-based study. Can J Gastroenterol 2010;24(1):33-39.
\end{abstract}

BACKGROUND: The wait time from cancer diagnosis to treatment has been a recent focus of cancer care in Canada.

OBJECTIVE: To examine the trends in wait times from patient presentation to treatment (overall health system wait time [OWT]) for colorectal cancer (CRC).

METHODS: Patients with colorectal adenocarcinomas, diagnosed between 2001 and 2005, and their first definitive treatments were identified from the population-based Manitoba Cancer Registry (Winnipeg, Manitoba). By linkage to Manitoba Health and Healthy Living's administrative databases, a patient's first gastrointestinal investigation (abdominal radiological imaging, lower gastrointestinal endoscopy or fecal occult blood test) before CRC diagnosis was identified. The index contact with the health care system was estimated from the date of the visit with the physician who ordered the first gastroenterological investigation. The OWT was defined as the time from the index contact to the first treatment, while diagnostic delay was defined as the time from the index contact to the diagnosis of CRC. Multivariate Cox regression analysis was performed to determine independent predictors of OWT.

RESULTS: The OWT was estimated for 2552 cases of CRC over the five years that were examined. The median OWT increased from 61 days in 2001 to 95 days in $2005(\mathrm{P}<0.001)$. Most of the increase was in diagnostic wait times (median of 44 days in 2001 versus 64 days in 2005 $[\mathrm{P}<0.001])$. Year of diagnosis, older age, urban residence and diagnosis at a teaching facility were independent predictors of OWT.

CONCLUSIONS: The OWT from presentation to treatment of CRC in Manitoba steadily increased between 2001 and 2005, mostly due to diagnostic delays.

\section{Le temps d'attente entre la présentation et le traitement du cancer colorectal : Une étude de population}

HISTORIQUE : Le temps d'attente entre le diagnostic de cancer et le traitement a récemment suscité l'intérêt dans les soins du cancer au Canada.

OBJECTIF : Examiner les tendances des temps d'attente entre la présentation du patient et le traitement (temps d'attente global dans le système de santé $[\mathrm{TAG}]$ ) pour le cancer colorectal (CCR).

MÉTHODOLOGIE : On a retracé les patients ayant des adénocarcinomes colorectaux, diagnostiqués entre 2001 et 2005, et leurs premiers traitements définitifs dans le registre manitobain du cancer (Winnipeg, Manitoba) fondé sur la population. En liant les bases de données administratives de Santé Manitoba, on a repéré la première exploration gastro-intestinale des patients (imagerie radiologique abdominale, endoscopie gastro-intestinale basse ou recherche de sang occulte dans les selles) avant le diagnostic de CCR. Le contact de référence avec le système de santé était évalué à compter de la date de visite chez le médecin qui avait demandé la première exploration gastroentérologique. Le TAG était défini comme le délai entre le contact de référence et le diagnostic de CCR. L'analyse de régression multivariée de Cox a permis de déterminer les prédicteurs indépendants de TAG.

RÉSULTATS : On a évalué le TAG pour 2552 cas de CCR pendant les cinq ans à l'étude. Le TAG médian est passé de 61 jours en 2001 à 95 jours en $2005(\mathrm{P}<0,001)$. La majeure partie de l'augmentation était causée par le temps d'attente avant le diagnostic (médiane de 44 jours en 2001 par rapport à 64 jours en $2005[\mathrm{P}<0,001])$. L'année de diagnostic, un âge plus avancé, un lieu de résidence en milieu urbain et le diagnostic dans un établissement d'enseignement étaient des facteurs indépendants de TAG. CONCLUSIONS : Le TAG entre la présentation et le traitement de CCR au Manitoba a augmenté régulièrement de 2001 à 2005, surtout à cause de délais avant le diagnostic.

Key Words: Colorectal cancer; Epidemiology; Wait times

W ait times for cancer diagnosis and treatment are a persistent concern to the public and have recently received increased attention in many countries. In the United Kingdom (UK), long wait times are believed to have contributed to worse outcomes for cancer patients, and this perception has led to a massive influx of funds and efforts to reduce wait times since 2000 (1). In Canada, the issue of wait times for health care has generated much attention since the September 2004 'Deal for a Decade' meeting of the Premiers and Prime Minister of Canada, which identified five priority service areas, including cancer treatment.

Wait times may be described as patient-related or health system-related. Patient-related delays refer to the time period

from the onset of symptoms to the patient's seeking of medical advice, which is not the subject of the present paper. Health system delays often refer to the time period from the first contact of the patient with the health care system to definitive treatment, but may also include delays in patient access to first contact. Health system delays can be further categorized as diagnostic delays (defined in the present study as time from the patient's first contact with the health care system to diagnosis) and treatment delays (time from diagnosis to definitive treatment).

Although patient satisfaction correlates inversely with both diagnostic and treatment delays (2), there is no national consensus on the maximum acceptable total wait times (overall

${ }^{1}$ Department of Internal Medicine; ${ }^{2}$ Department of Community Health Sciences, University of Manitoba; ${ }^{3}$ Epidemiology and Cancer Registry,

CancerCare Manitoba; ${ }^{4}$ Department of Surgery, University of Manitoba, Winnipeg, Manitoba

Correspondence: Dr Harminder Singh, Section of Gastroenterology, University of Manitoba, 804-715 McDermot Avenue,

Winnipeg, Manitoba R3E 3P4. Telephone 204-480-1311, fax 204-789-3972, e-mail singh@cc.umanitoba.ca

Received for publication March 12, 2009. Accepted April 13, 2009 
health system delay or wait time [OWT]) for cancer treatment in Canada. Most Canadian provinces have focused on treatment delays $(3,4)$. For diagnostic delays, the focus has been on wait time for radiological tests because they are the essential modality necessary for the diagnosis of most cancers $(3,4)$.

Colorectal cancer (CRC) is the second most common cause of cancer-related death and premature mortality in North America (5). The diagnostic work-up for CRC differs from most other common cancers in that most CRCs are diagnosed by lower gastrointestinal endoscopy. The recent advent of population-based CRC screening will add to the present workload for lower gastrointestinal endoscopies and could lead to longer OWT.

Using population-based data sources, we examined the trends in health system wait times for the first definitive treatment for CRC in Manitoba.

\section{METHODS}

\section{Databases}

The present retrospective cohort study used Manitoba's population-based cancer registry and the administrative databases maintained by Manitoba Health and Healthy Living (MHHL).

Manitoba Cancer Registry: Patients diagnosed with CRC were identified from the Manitoba Cancer Registry (MCR). The population-based MCR is maintained by CancerCare Manitoba, and receives reports on all cases of cancer in Manitoba as mandated by the Public Health Act. The coding and capture of cancer data are audited regularly by a standards setting group (the North American Association of Central Cancer Registries). The MCR has been consistently shown to be of very high quality, including very high levels of reporting completeness and histological verification (6).

The MCR contains key information regarding patient characteristics (age, sex and place of residence at diagnosis), the tumour (the anatomical site, histological type and date of diagnosis), treatment (the date and general nature of surgical, radiation and systemic treatment) as well as outcome (date of death, if applicable). Cancer stage at diagnosis is routinely recorded for all cases of CRC diagnosed in 2004 or later.

MHHL's administrative databases: Health care is publicly funded and administered in Manitoba, with no premiums for coverage. The MHHL is the provincial government agency responsible for the provision of health care to Manitoba residents. The MHHL maintains several administrative databases for the routine operation of the health care system (eg, to ensure the eligibility of health service recipients [Manitoba residents] to reimburse physicians for services, and to monitor use of the prescription drug plan). These data may also be used to identify key milestones in a patient's trajectory of care. Since 1984, every resident of Manitoba has been assigned a unique personal health identification number (PHIN) by MHHL. Longitudinal health services use and outcomes in the province can be ascertained by deterministic linkage of health use files and other databases that use PHINs as a key personal identifier. The accuracy and comprehensiveness of these administrative data have been previously established (7-9).

Record linkage: To maintain patient confidentiality, unique identifiers were removed from all the databases and linkage of the databases was performed using encrypted PHINs.

\section{CRC cases}

Patients diagnosed with CRC were identified from the MCR (International Classification of Diseases - Ninth Revision [ICD-9] codes 153.0 to 154.1 and 159.0 for cases diagnosed in 2001, and ICD-10 codes C18, C19, C20 and C26.0 for cases diagnosed from 2002 to 2005). Only individuals with first primary colorectal adenocarcinoma were included.

\section{Definition of wait times (Figure 1)}

Conservative estimates of the index contact with the health care system for symptoms leading to CRC diagnosis were developed. First, the date of CRC diagnosis was identified. Contacts with the health care system prior to the CRC diagnosis were determined by working backward in time. The first gastrointestinal investigation before the diagnosis of CRC, which may have included abdominal radiological imaging (barium enema, computerized tomography, ultrasound or plain abdominal films), lower gastrointestinal endoscopy or fecal occult blood test (FOBT), was identified. The physician visit before the patient's first gastroenterological investigation that was most likely to have generated the referral for the diagnostic investigation was considered to be the index contact with the health care system. For the radiological tests and the FOBT, the visit preceding the test with the ordering physician (indicative of the latest possible date of the index contact with the health care system) was identified. For lower gastrointestinal endoscopies, the endoscopist who performed the procedure was identified first. Then the date of the consultation with the endoscopist before or on the day of the endoscopy was identified. From the physician billing claims for the consultation, the referring physician was identified. The date of the last visit with the referring physician before the consultation was considered the index contact. Of note, all patients referred for endoscopy in the province are evaluated by an endoscopist before the procedure, on the day of procedure or at a previous visit. In addition, all billing claims for consultations in the province must specify the referring physician.

The dates of diagnosis and first treatment were determined from the MCR. The CRC cases diagnosed in 2006 and later were not included because the longitudinal MHHL data for these cases were not available at the time of the study.

The OWT was defined as the time from the index contact to the first definitive treatment. The diagnostic delay was defined as the time from the index contact to the ultimate diagnosis of CRC. The treatment delay was defined as the time from the date of diagnosis to the first definitive treatment for CRC.

\section{Statistical analysis}

Standard descriptive statistics were used to describe the study population and different categories of wait times. The trend for wait times from 2001 to 2005 was analyzed using the JonckheereTerpstra trend test.

All cases were followed up to the first treatment for CRC, migration from the province, death or one year after diagnosis. Stepwise, backward and forward multivariate Cox regression analyses were performed to determine the independent predictors of OWT. The potential predictors evaluated included age at diagnosis, sex, urban versus rural residence, socioeconomic status (SES), place of diagnosis (one of the two main teaching hospitals versus all others), year of CRC diagnosis, Charlson 


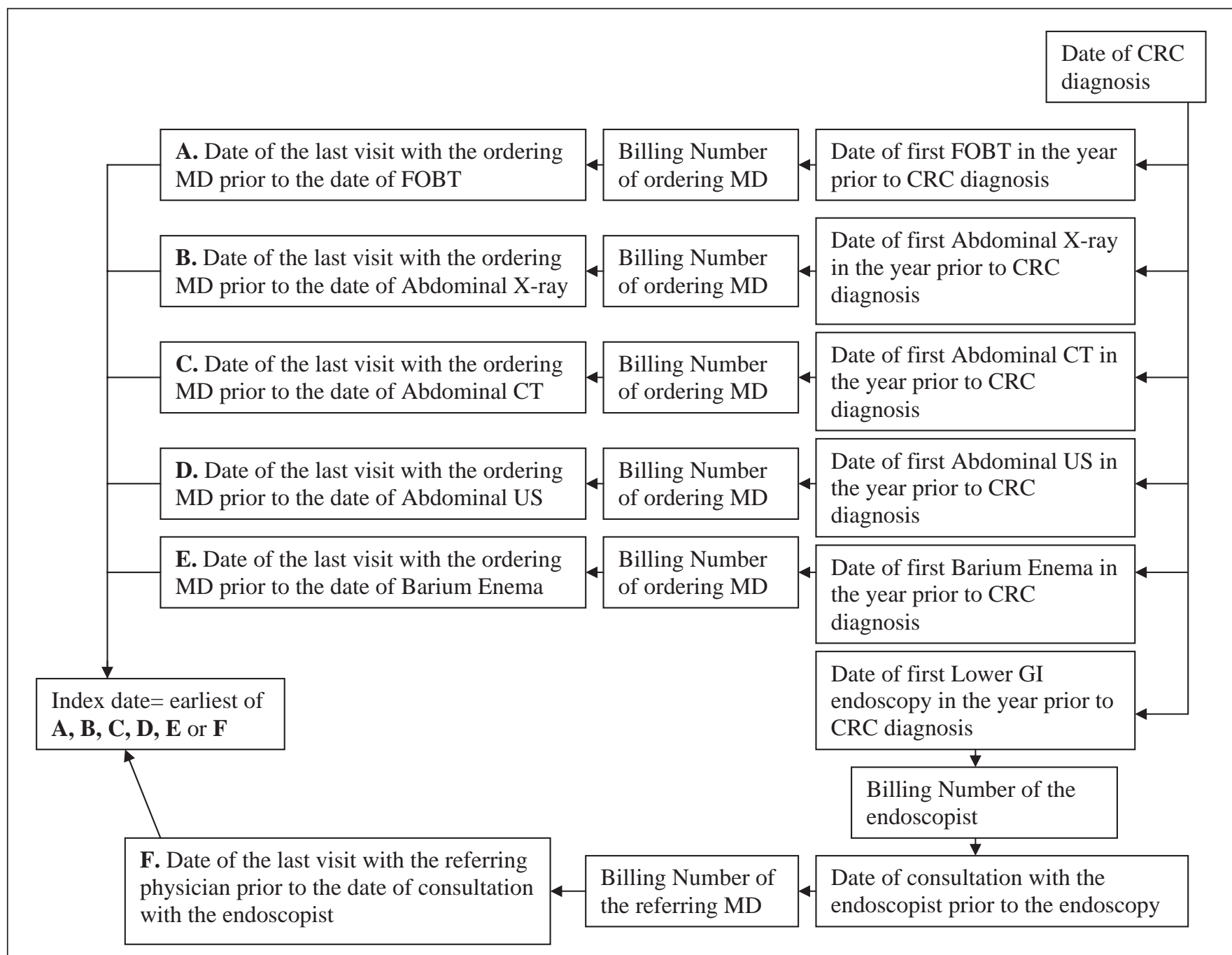

Figure 1) Time to diagnosis (diagnostic delay) was calculated as the time from the index contact to the date of colorectal cancer (CRC) diagnosis. The overall wait time was calculated as the time from index contact to the first treatment for colorectal cancer (see text for the description of data sources). CT Computed tomography; FOBT Fecal occult blood test; GI Gastrointestinal; MD Physician; US Ultrasound

comorbidity index $(\mathrm{CCI})$ score, type of initial test (radiological, lower gastrointestinal [GI] endoscopy or FOBT) and a hospital admission following an emergency room visit in the 30 days before the diagnosis of CRC. A Pearson contingency coefficient of 0.97 suggested a strong association between place of diagnosis and the treatment facility; hence, only the place of diagnosis was included in the analyses. The proportional hazards assumption was assessed by examining the Kaplan-Meier curves for categorical predictors and by assessing the significance of interactions of predictors with time in Cox models. Type of initial test and admission via an emergency room did not meet the proportional hazard assumption and, therefore, were considered as time-dependent variables in all analyses. Stratified Cox regression models were used to adjust for colonic and rectal site of cancer. Results were identical for the backward and forward regression models.

In additional analyses, the year of diagnosis was considered the principal predictor. Potential confounders were retained in the multivariate model if they resulted in a $10 \%$ or higher change in the crude hazard ratio (HR) of the principal predictor.
Lower HRs are reflective of longer time to event (ie, longer time to first treatment or OWT). HRs for the type of initial test (time-dependent variable) are reported at the time of index contact.

The SES was assigned based on the neighbourhood of residence using the neighbourhood-based socioeconomic factor index (SEFI), a previously validated measure (10-12). In the present study, data from the 2001 Statistics Canada census were used to determine SEFI. Individuals with higher SES have lower SEFI scores. The SEFI is standardized so that the overall mean score for Manitoba is 0 and each point increment represents a change of one SD.

The CCI score was determined from all hospital admissions in the year before the CRC diagnosis, using the algorithm developed and validated by Quan et al $(13,14)$ for ICD-9-CM and ICD-10. Individuals were categorized into those with CCI scores of 0 to 1,2 , and 3 or higher.

Rectosigmoid cancers were grouped with colon cancers because OWTs for these conditons were similar and significantly different from rectal cancers in univariate analysis. 
TABLE 1

Description of patients with first primary colorectal adenocarcinomas diagnosed from 2001 to 2005

\begin{tabular}{|c|c|c|c|c|c|}
\hline & \multicolumn{5}{|c|}{ Year of diagnosis } \\
\hline & $2001(n=673)$ & $2002(n=735)$ & $2003(n=665)$ & $2004(n=703)$ & $2005(n=666)$ \\
\hline Age, years (median [IQR]) & $73(62-80)$ & $72(62-79)$ & $72(62-80)$ & $72(61-79)$ & $72(60-81)$ \\
\hline Male sex & $356(53)$ & $395(54)$ & $372(56)$ & $373(54)$ & $365(55)$ \\
\hline Urban residence & $412(61)$ & $438(60)$ & $376(57)$ & $445(63)$ & $413(62)$ \\
\hline \multirow[t]{2}{*}{ SEFI, median (IQR) } & -0.11 & -0.23 & -0.26 & -0.08 & -0.14 \\
\hline & $(-0.84-0.71)$ & $(-0.91-0.73)$ & $(-0.93-0.54)$ & $(-0.78-0.67)$ & $(-0.87-0.65)$ \\
\hline Rectosigmoid & $92(14)$ & $72(10)$ & $57(9)$ & $72(10)$ & $62(9)$ \\
\hline Rectum & $150(22)$ & $182(25)$ & $154(23)$ & $170(24)$ & $167(25)$ \\
\hline \multicolumn{6}{|l|}{$\mathrm{CCl}$ score } \\
\hline $0-1$ & $273(41)$ & $296(40)$ & $302(45)$ & $269(38)$ & $279(42)$ \\
\hline 2 & $256(38)$ & $290(40)$ & $234(35)$ & $264(38)$ & $248(37)$ \\
\hline \multicolumn{6}{|l|}{ First test } \\
\hline Abdominal radiology & $254(38)$ & $261(36)$ & $219(33)$ & $272(39)$ & $232(35)$ \\
\hline LGI endoscopy & $296(44)$ & $318(43)$ & $314(47)$ & $266(38)$ & $265(40)$ \\
\hline $\begin{array}{l}\text { Admission through ER in } \\
\text { the month before CRC } \\
\text { diagnosis }\end{array}$ & $191(28)$ & $184(25)$ & $159(24)$ & $193(27)$ & $182(27)$ \\
\hline \multicolumn{6}{|l|}{ First treatment } \\
\hline Surgery & $590(88)$ & $630(86)$ & $572(86)$ & $603(86)$ & $558(84)$ \\
\hline Chemotherapy & $16(2)$ & $32(4)$ & $23(4)$ & $26(4)$ & $41(6)$ \\
\hline Radiotherapy & $12(2)$ & $10(1)$ & $10(2)$ & $13(2)$ & $4(1)$ \\
\hline No treatment & $55(8)$ & $63(9)$ & $60(9)$ & $61(9)$ & $63(9)$ \\
\hline
\end{tabular}

Data presented as $n$ (\%) unless specified otherwise. CCI Charlson comorbidity index; CRC Colorectal cancer; ER Emergency room; FOBT Fecal occult blood test; IQR Interquartile range; LGI Lower gastrointestinal; SEFI Socioeconomic Factor Index (measure of socioeconomic status)

Brandon and Winnipeg, the two largest cities in Manitoba, were considered to be urban centres.

SAS version 9.1 (SAS Institute Inc, USA) was used for data management and analyses. The present study was approved by the University of Manitoba's Health Research Ethics Board and MHHL's Health Information and Privacy Committee (Winnipeg, Manitoba).

\section{RESULTS}

Description of the study cohort

A total of 3442 individuals (54\% men, 46\% women; median age 72 years [interquartile range (IQR) 61 to 80]) were diagnosed with first primary colorectal adenocarcinoma between January 1, 2001, and December 31, 2005. Reflective of the population distribution in Manitoba, most individuals with CRC (61\%) were residents of the two major cities (Brandon and Winnipeg) at the time of diagnosis. There were 2264 individuals with colon cancer, 355 with rectosigmoid and 823 with rectal cancer. The median SEFI score was -0.15 (IQR -0.86 to 0.67), suggesting that the SES of the CRC patients was similar to that of the provincial population. Most patients had multiple comorbidities (CCI score 0 or $1,41 \% ; 2,38 \% ; 3$ or higher, 20\%). Of the 2357 individuals who had a colonoscopy in the year before the CRC diagnosis, 341 (15\%) had a consultation visit with the endoscopist on the day of the colonoscopy. The most common first treatment was surgery (86\%), which did not change over the years. Demographics with respect to year of diagnosis are presented in Table 1.

\section{Admission after an emergency room presentation}

Twenty-six per cent of individuals diagnosed with CRC (909 of 3442) were admitted through an emergency room in the month preceding the date of diagnosis, and this proportion did not change over time (Table 1).

\section{OWT}

The OWT delay was determined for 2552 cases. Of the 890 individuals for whom OWT was not determined, 302 did not receive any treatment and the majority of these were older (median age 81 years; IQR 73 to 87 ) and had more comorbidities (individuals with a CCI score of 3 or greater $[n=119]$ ). Furthermore, nearly one-half of these individuals died within two months of CRC diagnosis $(n=144)$. The index contact for 588 patients could not be determined using the algorithm. One hundred ninety-eight patients were likely regular patients of the endoscopists. These patients, instead of a recorded consultation with the endoscopist, had one or more other visits with the endoscopist before endoscopy. In the study years, a specialist could bill a consultation only if the patient had no other visit with the specialist in the preceding year. In addition, 259 patients for whom an index contact could not be tracked were admitted through an emergency room in the month before their CRC diagnosis - some of these patients may have been initially evaluated by one physician and the gastrointestinal investigation ordered by another physician.

The OWT steadily increased from 2001 to $2005(\mathrm{P}<0.001)$ (Table 2). The median OWT increased by approximately one 
TABLE 2

Wait times (days) with respect to year of diagnosis

\begin{tabular}{|c|c|c|c|c|c|c|}
\hline & \multicolumn{5}{|c|}{ Year of diagnosis } & \multirow[b]{2}{*}{$\mathbf{P}$} \\
\hline & 2001 & 2002 & 2003 & 2004 & 2005 & \\
\hline \multicolumn{7}{|l|}{$\overline{\mathrm{OWT}}$} \\
\hline Median & 61 & 73 & 81 & 89 & 95 & $<0.001$ \\
\hline 75th percentile & 115 & 140 & 143 & 147 & 180 & \\
\hline 90th percentile & 193 & 250 & 225 & 269 & 300 & \\
\hline \multicolumn{7}{|c|}{ OWT (excluding those with FOBT as first test) } \\
\hline Median & 51 & 59 & 70 & 76 & 71 & $<0.001$ \\
\hline 75th percentile & 98 & 118 & 125 & 125 & 141 & \\
\hline 90th percentile & 172 & 197 & 211 & 228 & 251 & \\
\hline \multicolumn{7}{|c|}{$\begin{array}{l}\text { OWT (excluding those with admission via emergency room in the } 30 \text { days } \\
\text { before CRC diagnosis) }\end{array}$} \\
\hline Median & 71 & 86 & 89 & 100 & 105 & $<0.001$ \\
\hline 75th percentile & 121 & 149 & 149 & 158 & 187 & \\
\hline 90th percentile & 192 & 259 & 225 & 282 & 298 & \\
\hline \multicolumn{7}{|l|}{ Diagnostic delay } \\
\hline Median & 44 & 47 & 58 & 60 & 64 & $<0.001$ \\
\hline 75th percentile & 92 & 111 & 118 & 118 & 141 & \\
\hline 90th percentile & 184 & 199 & 209 & 244 & 264 & \\
\hline \multicolumn{7}{|c|}{ Time from index contact to first colonoscopy* } \\
\hline Median & 37 & 43 & 54 & 55 & 54 & $<0.001$ \\
\hline 75th percentile & 85 & 96 & 111 & 101 & 117 & \\
\hline 90th percentile & 155 & 177 & 181 & 213 & 249 & \\
\hline \multicolumn{7}{|c|}{ Time from FOBT to first colonoscopy } \\
\hline Median & 67 & 77 & 74 & 81 & 88 & 0.003 \\
\hline 75th percentile & 131 & 121 & 133 & 136 & 183 & \\
\hline 90th percentile & 179 & 267 & 212 & 232 & 301 & \\
\hline \multicolumn{7}{|l|}{ Treatment delay } \\
\hline Median & 5 & 11 & 8 & 13 & 12 & 0.002 \\
\hline 75th percentile & 26 & 31 & 31 & 34 & 37 & \\
\hline 90th percentile & 43 & 55 & 48 & 62 & 63 & \\
\hline
\end{tabular}

*Limited to individuals who had colonoscopy on or before date of colorectal cancer (CRC) diagnosis. FOBT Fecal occult blood test; OWT Overall wait time

month, and the 75th percentile OWT by approximately two months. Over the years, the number of individuals whose first test was an FOBT increased from $111(17 \%)$ in 2001 to 150 (23\%) in 2005. The trend of increasing wait times persisted after excluding individuals whose first test was an FOBT $(\mathrm{P}<0.001)$, although the absolute increase was slightly less. As can be expected, on excluding the individuals seen in the emergency room just before their diagnosis, the median wait times were longer, but with similar time trends.

\section{Diagnostic and treatment delay}

There was a significant increase in the trend of both diagnostic and treatment delays, with the largest absolute increase in diagnostic delays (Table 2). The time to endoscopy increased over the years, including time from the index contact to the first colonoscopy, and the time from FOBT to colonoscopy.

\section{Multivariate analysis}

In the stepwise regression analysis, age at diagnosis, urban versus rural residence, place of diagnosis, year of diagnosis, CCI score, type of initial test and hospital admission via an emergency room in the 30 days before the diagnosis of CRC remained significant predictive factors of OWT (Table 3). The
TABLE 3

Adjusted hazard ratios for overall wait times

\begin{tabular}{|c|c|c|c|}
\hline Variable & Variable category & $\begin{array}{l}\text { Hazard } \\
\text { ratio* }\end{array}$ & $95 \% \mathrm{Cl}$ \\
\hline \multirow[t]{5}{*}{ Year of diagnosis } & 2001 & 1 & Reference \\
\hline & 2002 & 0.79 & $0.70-0.89$ \\
\hline & 2003 & 0.81 & $0.72-0.92$ \\
\hline & 2004 & 0.74 & $0.65-0.83$ \\
\hline & 2005 & 0.70 & $0.62-0.80$ \\
\hline \multirow{5}{*}{$\begin{array}{l}\text { Age at diagnosis, } \\
\text { years }\end{array}$} & $<50$ & 1 & Reference \\
\hline & $50-59$ & 0.97 & $0.81-1.16$ \\
\hline & $60-69$ & 0.99 & $0.84-1.16$ \\
\hline & $70-79$ & 0.86 & $0.73-1.01$ \\
\hline & $\geq 80$ & 0.69 & $0.58-0.81$ \\
\hline \multirow[t]{2}{*}{ Place of residence } & Rural & 1 & Reference \\
\hline & Urban & 0.88 & $0.81-0.96$ \\
\hline \multirow[t]{3}{*}{$\mathrm{CCl}$ score } & $0-1$ & 1 & Reference \\
\hline & 2 & 1.24 & $1.13-1.35$ \\
\hline & $\geq 3$ & 0.86 & $0.76-0.96$ \\
\hline \multirow[t]{3}{*}{ First $\mathrm{Gl}$ test $^{\dagger}$} & Lower GI endoscopy & 1 & Reference \\
\hline & FOBT & 0.36 & $0.30-0.42$ \\
\hline & Radiology & 0.79 & $0.72-0.87$ \\
\hline \multirow{2}{*}{$\begin{array}{l}\text { Prediagnosis ER } \\
\text { admission }^{\ddagger}\end{array}$} & No prediagnosis ER admission & 1.0 & Reference \\
\hline & Prediagnosis ER admission & 4.3 & $3.70-4.90$ \\
\hline \multirow[t]{2}{*}{ Place of diagnosis } & Nonteaching hospital & 1 & Reference \\
\hline & Teaching hospital & 0.84 & $0.76-0.93$ \\
\hline
\end{tabular}

Identical models developed by backward and forward stepwise regression analyses. *Lower hazard ratios indicate longer overall wait times; ${ }^{\dagger}$ Hazard ratio at the time of index contact; ${ }^{\ddagger}$ Admission through the emergency room within the 30 days preceding the diagnosis of colorectal cancer. CCI Charlson comorbidity index; ER Emergency room; FOBT Fecal occult blood test; GI Gastrointestinal

OWT in 2005 was 30\% longer than in 2001. Older individuals, urban residents, individuals with multiple comorbidities (CCI score of 3 or higher), diagnosis at one of the two teaching hospitals or FOBT as the first test, waited longer.

In an alternative analysis, no variable modified the HR of the principal variable (year of diagnosis) by more than $10 \%$ and, hence, no other variable was included in the final model. The HRs obtained in this analysis were similar to those obtained in the multivariate analysis (Table 4).

\section{DISCUSSION}

Our analysis suggests that the wait times for CRC treatment steadily increased in Manitoba between 2001 and 2005, with the largest absolute increase occurring in diagnostic delays. This is especially concerning because despite the advent of a population-based CRC screening program in the province, there has been no recent major augmentation of the main diagnostic service for CRC diagnosis - endoscopy capacity.

Although there remains a paucity of evidence that treatment delays result in worse clinical outcomes (15-18), both diagnostic and treatment delays result in major psychosocial stresses for cancer patients (19-22).

There are no uniformly accepted guidelines for maximum acceptable total health system delays in Canada. Few other countries have developed such guidelines. The UK has adopted a guideline stating that most cancer patients should 


\section{TABLE 4}

Unadjusted hazard ratios for overall wait times

\begin{tabular}{lcc}
\hline Year of diagnosis & Hazard ratio & 95\% Cl \\
\hline 2001 & 1 & Reference \\
2002 & 0.80 & $0.71-0.90$ \\
2003 & 0.82 & $0.72-0.93$ \\
2004 & 0.76 & $0.70-0.85$ \\
2005 & 0.70 & $0.62-0.80$ \\
\hline
\end{tabular}

When the year of diagnosis was considered to be the principal variable of interest, no variable modified the hazard ratios for the principal variable (year of diagnosis) by more than $10 \%$ and, hence, no other variable was included in the final model of this analysis

have treatment initiated within two months of referral by general practitioners (GPs) (23). In Denmark, the recommended maximum interval between referral and diagnostic work-up for CRC is 14 days, with commencement of treatment within an additional 14 days (24).

There are no previous Canadian population-based studies of OWT for CRC. A Canadian Association of Gastroenterology study (25) of several self-selected gastroenterology practices across the country found the wait times for access to specialists for digestive disease symptoms to be long throughout the country. Wait times determined in the present study were longer than those reported in a recent population-based Danish study (24) that found that the median wait time from a GP's referral to start of treatment was 28 days for colon cancer and 29 days for rectal cancer patients.

The results of the present study suggest that diagnostic delays contribute the most to health system delays for cancer care. The UK has attempted to reduce diagnostic delays by instituting a special pathway for those suspected of having a malignancy; there is a 'two-week rule' for maximum time from referral by a GP to consultation with a specialist for those referred through this pathway. This has led to a reduction in the time to diagnosis for those with CRC referred through this special pathway. However, most patients with CRC present with nonspecific symptoms (26) and continue to be diagnosed outside this pathway (27); consequently, there has been little reduction in average wait times $(23,28,29)$. Therefore, to reduce diagnostic delays, other authors have emphasized the need to reduce the time to diagnostic testing for all referrals for colorectal symptoms (30).

There are several potential reasons for the increasing wait times revealed in our study; future studies will be needed to specifically determine the predominant factors associated with most delays. An increasing number of individuals may be asymptomatic at diagnosis (ie, have screen-detected CRC), as suggested by the increasing number of individuals whose first test was an FOBT in the present study; however, the trend of increasing wait times persisted after excluding individuals whose first test was an FOBT. There may have been increased use of primary screening colonoscopy, which we were unable to distinguish because there are no separate physician billing codes for screening colonoscopy in the province. In recent years, there may have been an increased use of tests for staging after diagnosis, such as abdominal computed tomography scanning for all CRCs or pelvic magnetic resonance imaging and/or endoscopic ultrasound for rectal cancers; however, this should not affect the time to diagnosis. An increase in the age of the provincial population could have contributed to the wait times due to a larger number of individuals at risk for CRC and, hence, increased demand for CRC-related diagnostic and therapeutic services. However, Manitoba has a relatively stable population, with an increase of only 2000 individuals 65 years of age and older between 2001 and 2005. The wait times were longer when the first test was a radiological test; we suspect that these tests may have been ordered because of a perception among family physicians in the province that it is easier and faster to obtain a radiological test than a lower GI endoscopy. If CRC is suspected with a radiological test, most patients will subsequently undergo a lower GI endoscopy to visually confirm the diagnosis and obtain histological verification - this adds to the time to diagnosis. The number of colonoscopists in Manitoba remained relatively stable between 2001 and 2005 .

Regardless of the reasons for the delay, the increasing wait times have implications for policy makers and administrators. The provincial population-based CRC screening program (already in operation for approximately two years) is placing additional demands on the already limited diagnostic capacity in the province. The situation is likely similar in the rest of the country. Although the CRC screening programs have started or are about to start in several provinces, to the best of our knowledge, there has been no systematic expansion and/or reorganization of endoscopy services anywhere in Canada. Ontario is perhaps the only province in which additional resources have been provided, but these too, are limited to hospitals authorized by the Ontario CRC screening program and only for colonoscopies performed for the screening program. The results of our study should be interpreted in the context of the study strengths and limitations. Data sources used in the present study were reasonably robust; we used previously validated administrative databases, and the cancer diagnoses were reliable and complete. Of note, cancer registrars in Manitoba actively investigate all cancer reports and, therefore, the MCR does not rely on passive reporting alone, as is the case in some other jurisdictions. Some of the predictive factors for longer wait times for health care such as residence in an urban centre, are similar to those found in other studies for other conditions, which provides face validity for the present study (31).

The estimation of the first contact with the health system is optimistic and we may have underestimated some of the OWTs. It is possible that the physicians may not have investigated the patient for a CRC-related complaint at the first visit and started the process at a subsequent visit (ie, 'primary care delay'). It is also possible that physicians had additional visits with the patient after ordering an investigation and before the investigation was performed - in such cases, we would have underestimated the wait time. However, this underestimation is likely nondifferential with respect to the year of diagnosis, time trends or the categories of predictors of wait times in our study. Moreover, despite the potential for underestimation, the 75th and 90th percentiles of OWT and diagnostic delays were long and getting progressively longer.

While the present study was retrospective, there is a paucity of prospectively collected data for cancer treatment OWTs because most of the prospective collection of data has focused on treatment delays after diagnosis. The data did not allow us to separate screen-detected CRC patients from those who presented with clinical symptoms, but increasing delays in both 
categories are concerning. With our algorithm, we could not track the OWT for all patients.

Additionally, we did not have information regarding cancer stage at diagnosis for the years 2001 to 2003 and, therefore, did not include cancer stage in our models; however, there is no consistent association of stage at diagnosis and wait times for $\mathrm{CRC}$ diagnosis or treatment reported in the literature. A recent meta-analysis (32) found no association between diagnostic or therapeutic delay and stage of colorectal cancer. Moreover, in Manitoba, there has been no stage shift in CRCs diagnosed over the past few years $(\mathrm{P}=0.39$ for trends in the stage of CRCs diagnosed in 2004, 2005 and 2006).

\section{CONCLUSION}

Health system delays for CRC treatment are increasing in Manitoba, with the largest absolute increase occurring in diagnostic delays. Further studies are needed to determine the reasons for these delays and the impact of this magnitude of increase on clinical outcomes, patient satisfaction and acceptance, and psychological stress.

CONFLICTS OF INTEREST: The authors report no conflicts of interest. The results and conclusions are those of the authors, and no official endorsement by Manitoba Health and Healthy Living is intended or should be inferred. Dr Harminder Singh is the guarantor of the article.

FUNDING: This study was funded by the CancerCare Manitoba Foundation. Dr Singh was supported, in part, by the Dr FW Du Val Clinical Research Professorship Award.

\section{REFERENCES}

1. Hanna SJ, Muneer A, Khalil KH. The 2-week wait for suspected cancer: Time for a rethink? Int J Clin Pract 2005;59:1334-9.

2. Porter GA, Inglis KM, Wood LA, Veugelers PJ. Access to care and satisfaction in colorectal cancer patients. World J Surg 2005;29:1444-51.

3. Manitoba Health. Working for better health care sooner. Report to Manitobans on health care services. <http://www gov mb ca/health/ waittime/report2006.pdf> (Version current at May 1, 2006).

4. Ontario Ministry of Health and Long-Term Care. Wait times targets. <http://www health gov on ca/transformation/wait times/ providers/wt_target.html $>$ (Version current at October 17, 2008).

5. Canadian Cancer Society/National Cancer Institute of Canada. Canadian Cancer Statistics 2008. Toronto, Canada, 2008.

6. North American Association of Central Cancer Registeries Inc. Section II: Average-annual Registry-specific Cancer Incidence by Race and Sex. In: Hotes Ellison J, Wu XC, McLaughlin C, et al, eds. Cancer in North America: 1999-2003. Vol I: Incidence. North American Asociation of Central Cancer Registeries Inc, 2006:325.

7. Robinson JR, Young TK, Roos LL, Gelskey DE. Estimating the burden of disease. Comparing administrative data and self-reports. Med Care 1997;35:932-47.

8. Roos LL, Mustard CA, Nicol JP, et al. Registries and administrative data: Organization and accuracy. Med Care 1993;31:201-12.

9. Roos LL Jr, Nicol JP, Cageorge SM. Using administrative data for longitudinal research: Comparisons with primary data collection. J Chronic Dis 1987;40:41-9.
10. Martens PJ, Frohlich N, Carriere KC, Derksen S, Brownell M. Embedding child health within a framework of regional health: Population health status and sociodemographic indicators. Can J Public Health 2002;93(Suppl 2):S15-S20.

11. Martens PJ, Derksen S, Gupta S. Predictors of hospital readmission of Manitoba newborns within six weeks postbirth discharge: A population-based study. Pediatrics 2004;114:708-13.

12. Frohlich N, Mustard C. A regional comparison of socioeconomic and health indices in a Canadian province. Soc Sci Med 1996;42:1273-81.

13. Quan H, Sundararajan V, Halfon P, et al. Coding algorithms for defining comorbidities in ICD-9-CM and ICD-10 administrative data. Med Care 2005;43:1130-9.

14. Sundararajan V, Quan H, Halfon P, et al. Cross-national comparative performance of three versions of the ICD-10 Charlson index. Med Care 2007;45:1210-5.

15. Coates AS. Breast cancer: Delays, dilemmas, and delusions. Lancet 1999;353:1112-3.

16. Roncoroni L, Pietra N, Violi V, Sarli L, Choua O, Peracchia A. Delay in the diagnosis and outcome of colorectal cancer: A prospective study. Eur J Surg Oncol 1999;25:173-8.

17. Wurtz LD, Peabody TD, Simon MA. Delay in the diagnosis and treatment of primary bone sarcoma of the pelvis. J Bone Joint Surg Am 1999;81:317-25.

18. Christensen ED, Harvald T, Jendresen M, Aggestrup S, Petterson G. The impact of delayed diagnosis of lung cancer on the stage at the time of operation. Eur J Cardiothorac Surg 1997;12:880-4.

19. Gray RE, Fitch MI, Phillips C, Labrecque M, Klotz L. Presurgery experiences of prostate cancer patients and their spouses. Cancer Pract 1999; 7:130-5.

20. Julian-Reynier C, Eisinger F, Chabal F, et al. Time elapsing from cancer diagnosis and anxiety in women attending cancer genetic clinics. Oncol Rep 1998;5:885-8.

21. Rapoport Y, Kreitler S, Chaitchik S, Algor R, Weissler K. Psychosocial problems in head-and-neck cancer patients and their change with time since diagnosis. Ann Oncol 1993;4:69-73.

22. Weisman AD, Worden JW. The existential plight in cancer: Significance of the first 100 days. Int J Psychiatry Med 1976;7:1-15.

23. Raje D, La TS, Mukhtar H, Oshowo A, Ingham CC. Changing trends in the management of colorectal cancers and its impact on cancer waiting times. Colorectal Dis 2006;8:140-4.

24. Korsgaard M, Pedersen L, Laurberg S. Delay of diagnosis and treatment of colorectal cancer - a population-based Danish Study. Cancer Detect Prev 2008;32:45-51.

25. Leddin D, Armstrong D, Barkun AN, et al. Access to specialist gastroenterology care in Canada: Comparison of wait times and consensus targets. Can J Gastroenterol 2008;22:161-7.

26. Bjerregaard NC, Tottrup A, Sorensen HT, Laurberg S. Diagnostic value of self-reported symptoms in Danish outpatients referred with symptoms consistent with colorectal cancer. Colorectal Dis 2007;9:443-51.

27. Thorne K, Hutchings H, Elwyn G. The effects of the two-week rule on NHS colorectal cancer diagnostic services: A systematic literature review. BMC Health Serv Res 2006;6:43.

28. Chohan DPK, Goodwin K, Wilkinson S, Miller R, Hall NR. How has the 'two-week wait' rule affected the presentation of colorectal cancer? Colorectal Dis 2005;7:450-3.

29. Rai S, Kelly MJ. Prioritization of colorectal referrals: A review of the 2-week wait referral system. Colorectal Dis 2007;9:195-202.

30. Scott MA, Knight A, Brown K, Novell JR. A single common urgent pathway for all colorectal referrals reduces time to diagnosis and treatment. Colorectal Dis 2006;8:766-71.

31. De Coster C, Chateau D, Dahl M, Soodeen R, McKeen N. Waiting Times for Surgery, Manitoba 1999/2000 to 2003/04. Winnipeg: Manitoba Centre for Health Policy, 2007.

32. Ramos M, Esteva M, Cabeza E, Llobera J, Ruiz A. Lack of association between diagnostic and therapeutic delay and stage of colorectal cancer. Eur J Cancer 2008;44:510-21. 


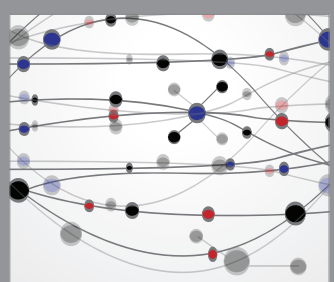

The Scientific World Journal
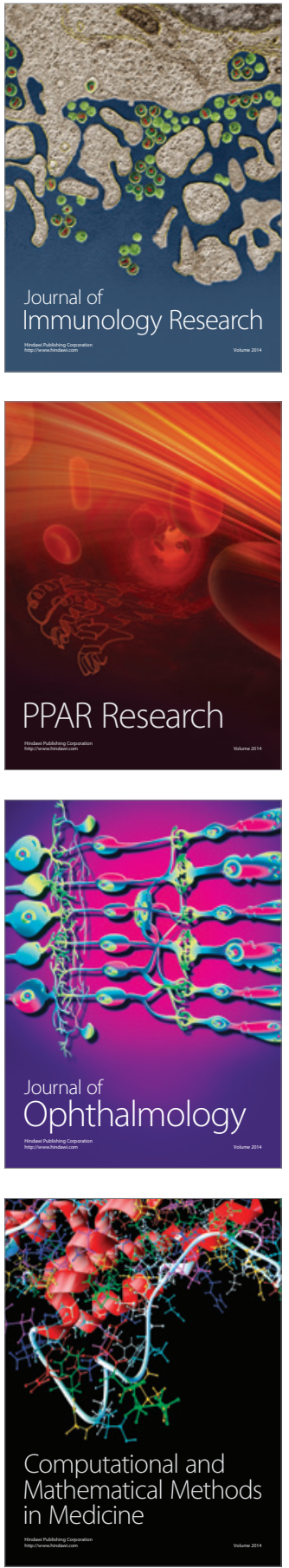

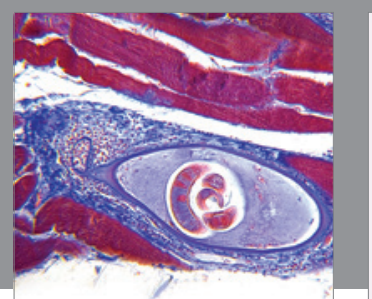

Gastroenterology Research and Practice

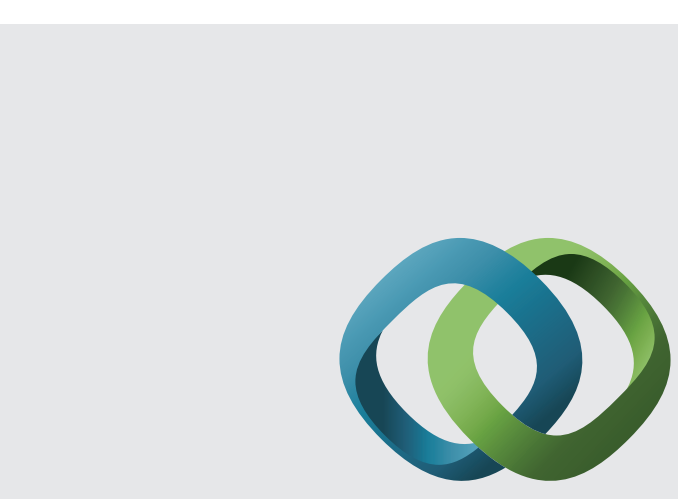

\section{Hindawi}

Submit your manuscripts at

http://www.hindawi.com
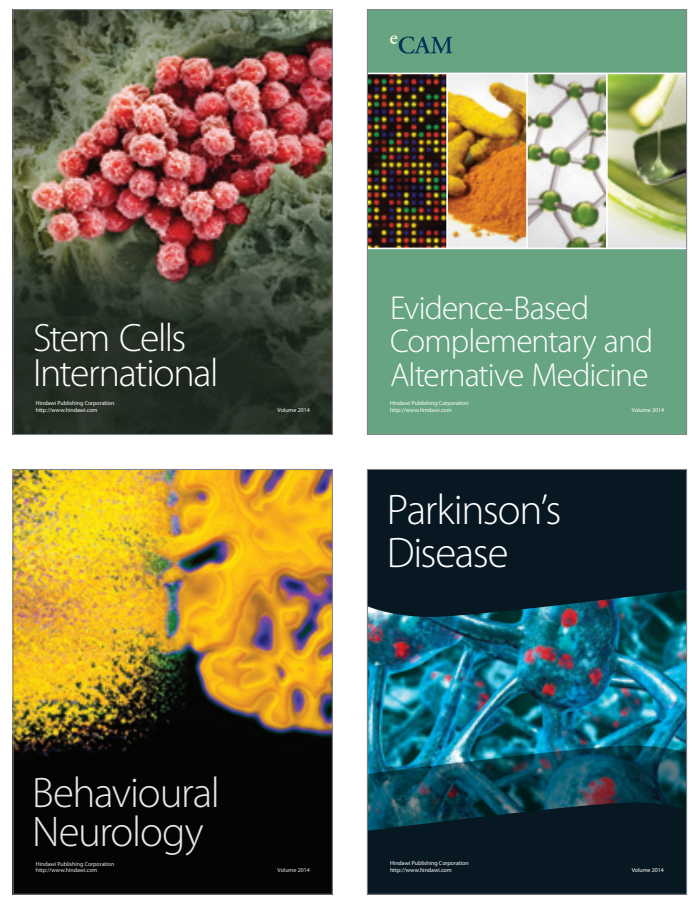
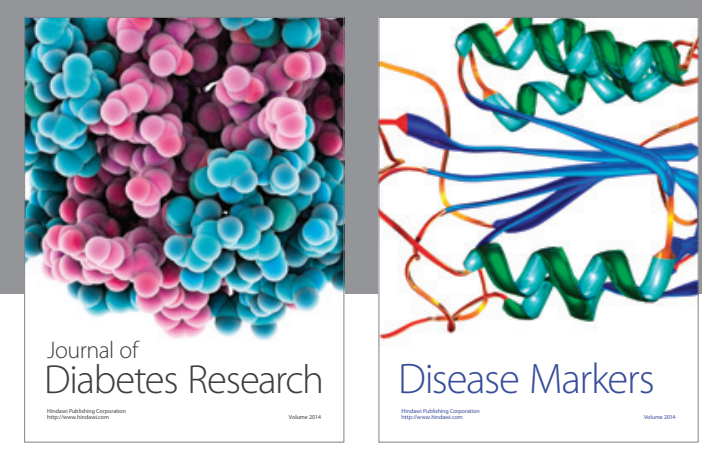

Disease Markers
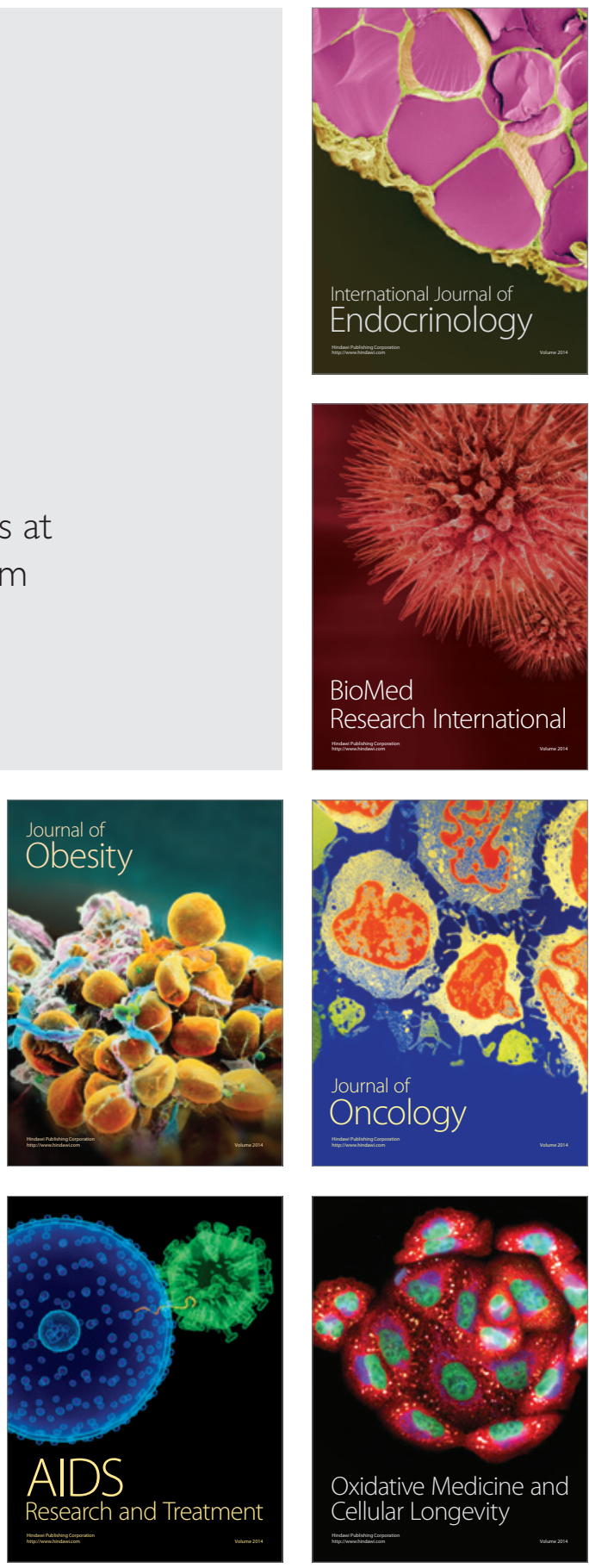